\title{
Gene therapy: Where do we stand?
}

\author{
Sushmita Roy ${ }^{1}$, Md. Abdullah Yusuf ${ }^{2}$ \\ 1. Assistant Professor, Department of Microbiology, Enam Medical College, Dhaka. \\ 2. Lecturer, Department of Microbiology, ShaheedSuhrawardy Medical College, Dhaka.
}

\begin{abstract}
The concept of transferring genes to tissues for clinical applications has been discussed for nearly half a century, but the ability to manipulate genetic material via recombinant DNA technology has brought this goal to reality. 'Gene Therapy' covers both the research and clinical applications of the new genetic therapy techniques currently being developed. The application of molecular biology has revolutionized researchers understanding of many diseases and has been readily applied for diagnostic purposes. Now-a-day this is originally conceived as a way to treat life-threatening disorders (inborn errors, cancers) refractory to conventional treatment, gene therapy now is considered for many non-life-threatening conditions, including those adversely affecting a patient's quality of life. The lack of suitable treatment has become a rational basis for extending the scope of gene therapy. It is not very far, the justifiable optimism that with increased biotechnological improvement, gene therapy will become a standard part of clinical practice.
\end{abstract}

Key Words: Recombinant DNA technology, Gene Therapy, Biotechnological improvement

\section{Introduction}

The term "gene therapy" was coined to distinguish it from the Orwellian connotations of human genetic engineering, which, in turn, was derived from the term "genetic engineering." Genetic engineering was first used at the Sixth International Congress of Genetics held in 1932 and was taken to mean the application of genetic principles to animal and plant breeding. ${ }^{1}$ Once the basis of gene transfer in bacteria was established in the 1960s, gene transfer into animals and humans using either viral vector and/or genetically modified cultured cells became inevitable. ${ }^{2}$ Despite the early exposition of the concept of gene therapy, progress awaited the advent of recombinant DNA technology. Viral genomes were used for the development of the first efficient methods for gene transfer into mammalian cells in culture. ${ }^{3}$ In the late 1970 s, early transfection techniques were combined with selection systems for cultured cells and recombinant DNA technology. Efficient retroviral vectors and other gene transfer methods have permitted convincing demonstrations of efficient phenotype correction in vitro and in vivo. ${ }^{4}$ The journey of gene transfer from laboratory to clinic has been slow and fraught with many challenges and barriers. Despite the development of the initial technology in the early 1970s, a standard clinical treatment involving gene therapy remains to be seen. The translational path of gene transfer thus far, both pitfalls and successes, can serve as a study not only in navigating ethical and safety concerns, but also in the importance of scientist-public interactions. ${ }^{5}$

Scientists first took the step of trying to introduce genes directly into human cells, focusing on diseases caused by single-gene defects, such as cystic fibrosis, hemophilia, muscular dystrophy and sickle cell anemia. ${ }^{6}$ However, this has proven more difficult than modifying bacteria, primarily because of the problems involved in carrying large sections of DNA and delivering them to the specific site on the large genome. Recently, most gene therapy studies are aimed at cancer and hereditary diseases. ${ }^{7}$

\section{Viruses}

\section{Vectors Used In Gene Therapy}

All viruses bind to their hosts and introduce their genetic material into the host cell as part of their replication cycle. This genetic material contains basic 'instructions' of how to produce more copies of these viruses, directing the body's normal production machinery to serve the needs of the virus. Some viruses physically insert their genes into the host's genome (e.g., Retrovirus). This incorporates the genes of that virus among the genes of the host cell for the life span of that cell. ${ }^{8}$ Molecular biologists realized that such viruses could be used as vehicles to carry genes of interest into a human cell. First, a scientist would remove the genes in the virus that cause disease. Then they would replace those genes with genes encoding the desired effect (e.g., insulin producing gene). ${ }^{9}$ All this is clearly an oversimplification, and numerous problems exist that prevent gene therapy using viral vectors. However, this basic mode of gene introduction currently shows much promise and scientists are working hard to fix any potential problems that could exist.

Adenoviruses introduce their DNA molecule during into the host. The genetic material of the adenoviruses is not incorporated into the host cell's genetic material. The DNA molecule is left free in the nucleus of the host cell, and the instructions in this extra DNA molecule are transcribed just like any other gene. 
The only difference is that these extra genes are not replicated when the cell is about to undergo cell division so the descendants of that cell will not have the extra gene. ${ }^{10}$ As a result, treatment with the adenovirus will require readministration in a growing cell population although the absence of integration into the host cell's genome should prevent the type of cancer seen in the SCID trials. ${ }^{11}$

Table 1. List of commonly used vectors for cancer gene therapy as well as their advantages and disadvantages ${ }^{12}$

\begin{tabular}{lll}
\hline Vector & Advantages & Disadvantages \\
\hline Adenovirus & $\begin{array}{l}\text { Easy to produce, can achieve } \\
\text { high titre, high efficiency of genetransfer }\end{array}$ & $\begin{array}{l}\text { Large DNA virus, many viral } \\
\text { genes, often Immunogenic }\end{array}$ \\
$\begin{array}{l}\text { Adeno-associated } \\
\text { virus }\end{array}$ & $\begin{array}{l}\text { Relatively easy to produce, hasability for } \\
\text { gene integration }\end{array}$ & $\begin{array}{l}\text { Wide type Adenovirus } \\
\text { contamination }\end{array}$ \\
Retrovirus & $\begin{array}{l}\text { Can be made through packagingcells, has } \\
\text { ability for geneintegration }\end{array}$ & $\begin{array}{l}\text { Low efficiency of gene } \\
\text { transfer, dividing cells only }\end{array}$ \\
Herpesvirus & $\begin{array}{l}\text { Has Neurotropic affinity, can beapplied to } \\
\text { neurons or glioma }\end{array}$ & $\begin{array}{l}\text { Large DNA virus, many viral } \\
\text { genes, Immunogenic }\end{array}$ \\
$\begin{array}{l}\text { Viral replicons: } \\
\text { Semliki Forest virus }\end{array}$ & $\begin{array}{l}\text { Easy production, less } \\
\text { immunogenic }\end{array}$ & Difficult to purify \\
Non-viral vectors & Simple, easy to make and easy touse & Low efficiency
\end{tabular}

This vector system has been promoted for treating cancer and indeed the first gene therapy product to be licensed to treat cancer. Gendicine, an adenoviral p53-based gene therapy was approved by the Chinese FDA in 2003 for treatment of head and neck cancer. ${ }^{13}$

\section{Naked DNA}

This is the simplest method of non-viral transfection with simple large scale production and low host immunogenicity. ${ }^{14}$ Clinical trials carried out of intramuscular injection of a naked DNA plasmid have occurred with some success; however, the expression has been very low in comparison to other methods of transfection. In addition to trials with plasmids, there have been trials with naked PCR product, which have had similar or greater success. ${ }^{15}$ This success, however, does not compare to that of the other methods, leading to research into more efficient methods for delivery of the naked DNA such as electroporation, sonoporation, and the use of a "gene gun", which shoots DNA coated gold particles into the cell using high pressure gas or a inverted .22 caliber gun. ${ }^{16}$

\section{Oligonucleotides}

The use of synthetic oligonucleotides in gene therapy is to inactivate the genes involved in the disease process. There are several methods by which this is achieved. One strategy uses antisense specific to the target gene to disrupt the transcription of the faulty gene. ${ }^{17}$ Another uses small molecules of RNA called siRNA to signal the cell to cleave specific unique sequences in the mRNA transcript of the faulty gene, disrupting translation of the faulty mRNA, and therefore expression of the gene. ${ }^{18}$

\section{Lipoplexes and Polyplexes}

The newer molecules, lipoplexes and polyplexes, have been created that have the ability to protect the DNA from undesirable degradation during the transfection process. Plasmid DNA can be covered with lipids in an organized structure like a micelle or a liposome. When the organized structure is complexed with DNA it is called a lipoplex. The most common use of lipoplexes has been in gene transfer into cancer cells, where the supplied genes have activated tumor suppressor control genes in the cell and decrease the activity of oncogenes. Complexes of polymers with DNA are called polyplexes which consist of cationic polymers and their production is regulated by ionic interactions. ${ }^{19}$

\section{Hybrid methods}

Due to every method of gene transfer having shortcomings, there have been some hybrid methods developed that combine two or more techniques. Virosomes are one example; they combine liposomes with an inactivated HIV or influenza virus. ${ }^{20}$ This has been shown to have more efficient gene transfer in respiratory epithelial cells than either viral or liposomal methods alone. 


\section{Dendrimers}

The surface of the dendrimer particle may be functionalized in many ways and many of the properties of the resulting construct are determined by its surface. In particular it is possible to construct a cationic dendrimer, i.e. one with a positive surface charge. When in the presence of genetic material such as DNA or RNA, charge complimentarity leads to a temporary association of the nucleic acid with the cationic dendrimer. On reaching its destination the dendrimer-nucleic acid complex is taken into the cell via endocytosis. ${ }^{21}$

\section{Clinical Trials of Gene Therapy}

To date, over 1800 gene therapy clinical trials have been completed, are ongoing or have been approved worldwide. ${ }^{22}$ However, a number of widely reported adverse events have focused attention on associated risks ahead of the exciting therapeutic progress being made. In 2000, the optimism of the gene therapy research community was bolstered by the first report of successful treatment of a genetic disease by gene therapy. ${ }^{23}$ The condition, X-linked severe combined immunodeficiency (SCID-X1), is characterized by recurrent infection as a result of an absence of cell-mediated and humoral immunity. ${ }^{24}$ Importantly, the majority of treated infants underwent full immunological reconstitution. Adenosine deaminase-deficiency (ADA-SCID) is another primary immunodeficiency for which gene therapy is showing great promise in the clinic. In this trial for Wiscott-Aldrich syndrome, the results for ten patients have been reported. Following treatment, the clinical condition of the patients improved and long-term engraftment of gene-corrected cells was observed in the bone marrow. ${ }^{25}$ Thus far, most of the clinical trials in gene therapy have been aimed at the treatment of cancer. A range of strategies has been applied to treat cancer, from inserting tumour suppressor genes to immunotherapy, oncolyticvirotherapy and gene directed enzyme pro-drug therapy. ${ }^{26}$ Cardiovascular gene therapy is the third most popular application for gene therapy at trials. The expectation is that gene therapy will provide a new avenue for therapeutic angiogenesis, myocardial protection, regeneration and repair, prevention of re-stenosis following angioplasty, prevention of bypass graft failure. ${ }^{27}$

Many gene therapy protocols in clinical or preclinical trials are showing great promise. Two notable examples include the treatment of haemophilia B and lipoprotein lipase deficiency in adults. In both of these trials, however, only a transient clinical benefit was observed as a result of the immune responses directed against vector constituents, with resultant cell-mediated destruction of the gene-corrected cells in the liver and muscle, respectively. ${ }^{28}$ Another strategy being considered is the use of regulated expression cassettes containing microRNA (miRNA) sequences. Inclusion of miRNA targeting haematopoietic lineages to eliminate or reduce off-target gene expression in professional antigen presenting cells has allowed the stable correction of a haemophilia B mouse model and also been shown to induce antigen-specific immunologic tolerance. ${ }^{29}$

\section{Conclusion}

The overall trajectory of clinical trial activity in the field of gene therapy is positive, with increasing evidence of clinical benefits across a growing number of diseases. The field has also reacted positively to the occurrence of vector-related adverse events and other lessons learnt from earlier gene therapy trials. These lessons are now being accommodated in an iterative manner in ongoing trial activity, which is delivering further exciting progress. Although rigorous preclinical efficacy and safety testing remains a foundation stone of clinical trials, much of the knowledge required to drive further progress which can only come from well designed and executed clinical trials.

\section{References}

[1]. Wolff JA, Lederberg J. An early history of gene transfer and therapy. Hum Gene Ther. 1994; 5(4):469-80.

[2]. Friedmann T. A brief history of gene therapy. Nat Genet. 1992; 2(2):93-8.

[3]. Greenberg AJ, McCormick J, Tapia CJ, Windebank AJ. Translating gene transfer: a stalled effort. ClinTransl Sci. 2011; 4(4):279-81.

[4]. Kang HJ, Bartholomae CC, Paruzynski A. Retroviral gene therapy for X-linked chronic granulomatous disease: results from Phase I/II trial. MolTher 2011; 19: 2092-2101.

[5]. Francisco Martí n, KarimBenabdellah, MariénCobo, PilarMuñoz, Per Anderson and Miguel G. Toscano. New Vectors for Stable and Safe Gene Modification. In: Chunsheng Kang (ed) Gene Therapy - Developments and Future Perspectives.2011: 1-30.

[6]. Edelstein ML, Abedi MR, Wixon J. Gene therapy clinical trials worldwide to 2007 - an update. J Gene Med 2007; 9: 833-842.

[7]. Samantha LG, Ian EA, Michael LE, Mohammad RA, Jo Wixon.Gene therapy clinical trials worldwide to $2012-$ an update. The Journal of Gene Medicine 2013; 15(2): 65-77.

[8]. Penn Medicine presents HIV gene therapy trial data at CROI 2009. EurekAlert! 10 February 2009

[9]. Callejas D, Mann CJ, Ayuso E, Lage R, Grifoll I, Roca C, Andaluz A, et al. "Treatment of Diabetes and Long-term Survival Following Insulin and Glucokinase Gene Therapy". Diabetes 2013.

[10]. Marshall E. Gene therapy death prompts review of adenovirus vector. Science 1999; 286: 2244-2245.

[11]. Sokolic R, Kesserwan C, Candotti F. Recent advances in gene therapy for severe congenital immunodeficiency diseases. CurrOpinHematol 2008; 15: 375-380.

[12]. David Good, Wei Duan, JozefAnné and Ming Wei (2011). Cancer Gene Therapy- Developments and Future Perspectives. In: Prof. Chunsheng Kang (ed.). Gene Therapy - Developments and Future Perspectives. 2011;301-314.

[13]. Morgan RA, Dudley ME, Wunderlich JR, Hughes MS, Yang JC, Sherry RM, Royal RE, Topalian SL, et al. "Cancer Regression in Patients After Transfer of Genetically Engineered Lymphocytes". Science 2006;314 (5796): 126-129. 
[14]. Sack BK, Herzog RW. Evading the immune response upon in vivo gene therapy with viral vectors. CurrOpinMolTher 2009; 11: 493503.

[15]. Ogino S, Gulley ML, den Dunnen JT. Standard mutation nomenclature in molecular diagnostics: practical and educational challenges. J MolDiagn 2007; 9: 1-6.

[16]. Ferrua F, Brigida I, Aiuti A. "Update on gene therapy for adenosine deaminase-deficient severe combined immunodeficiency". Current Opinion in Allergy and Clinical Immunology 2010; 10 (6): 551-556.

[17]. Annoni A, Brown BD, Cantore A. In vivo delivery of a microRNA-regulated transgene induces antigen-specific regulatory T cells and promotes immunological tolerance. Blood 2009; 114: 5152-5161.

[18]. Brown BD, Venneri MA, Zingale A Zingale A, Sergi LS, Naldini L. Endogenous microRNA regulation suppresses transgene expression in haematopoietic lineages and enables stable gene transfer. Nat Med 2006; 12: 585-591.

[19]. European Community clinical trials database (EudraCT). 2013. http://eudract.emea.europa.eu/ [4 February 2013].

[20]. Brown BD, Cantore A, Annoni A. A microRNA-regulated lentiviral vector mediates stable correction of haemophilia B mice. Blood 2007; 110: 4144-4152.

[21]. Gene therapy deserves a fresh chance". Nature 2009; 461 (7268): 1173-2009.

[22]. Kohn DB. Update on gene therapy for immunodeficiencies. ClinImmunol 2010; 135: 247-254.

[23]. Hacein-Bey-Abina S, Le Deist F, Carlier F. Sustained correction of X-linked severe combined immunodeficiency by ex vivo gene therapy. N Engl J Med 2002; 346: 1185-1193.

[24]. Hacein-Bey-Abina S, Hauer J, Lim A. Efficacy of gene therapy for X-linked severe combined immunodeficiency. N Engl J Med 2010; 363: 355-364.

[25]. Klein C. Effective gene therapy for children with Wiskott-Aldrich syndrome. 2010. http://wwwidwonlinede/pages/de/news396307\%3E2010 [4 February 2013].

[26]. Morgan RA, Dudley ME, Wunderlich JR. Cancer regression in patients after transfer of genetically engineered lymphocytes. Science 2006; 314: 126-129.

[27]. Hahn W, Pyun WB, Kim DS, Yoo WS, Lee SD, Won JH, Shin GJ, et al. "Enhanced cardioprotective effects by coexpression of two isoforms of hepatocyte growth factor from naked plasmid DNA in a rat ischemic heart disease model". The Journal of Gene Medicine 2011; 13 (10): 549-555.

[28]. Penman, Danny. Subtle gene therapy tackles blood disorder. New Scientist 2002.

[29]. Nathwani AC, Tuddenham EG, Rangarajan S, et al. Adenovirus-associated virus vector-mediated gene transfer in haemophilia B. New Engl J Med 2011; 365: 2357-2365. 